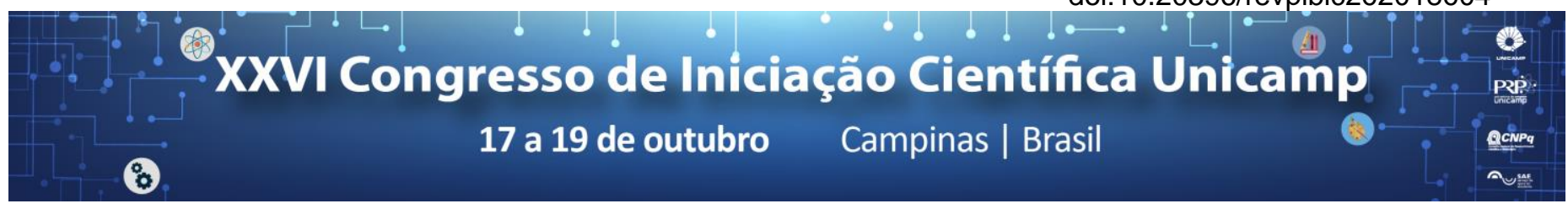

\title{
Implementação de uma Liga Acadêmica de Ética e Bioética como auxílio ao ensino
}

\author{
Hugo D. Ceccato*, Thiago M. Santos
}

\section{Resumo}

O ensino de Ética e Bioética nos cursos de medicina ainda encontra diversas barreiras, seja pelo espaço restrito dentro do currículo, seja pela falta de capacitação docente. Nesse contexto, a implementação de uma Liga de Ética e Bioética pode vir a ser um instrumento importante para aproximar alunos e docentes em busca de novos modelos de ensino. $\mathrm{O}$ presente estudo relata o primeiro ano de implantação da Liga de Ética e Bioética (LiEBe) do curso de Medicina da Faculdade de Ciências Médicas da Universidade de Campinas.

\section{Palavras-chave:}

Ensino médico; Ética; Bioética.

\section{Introdução}

Liga Acadêmica em Medicina (LAM) é uma organização estudantil sem fins lucrativos embasada por ensino, extensão e pesquisa com o objetivo de aprimorar e adquirir habilidades através de uma estrutura mais versátil, quando comparada ao currículo formal. $\mathrm{O}$ ensino de Ética e Bioética dentro dos cursos de medicina, por sua vez, ainda é fonte de escassos estudos sendo que os poucos existentes apontam para uma estrutura que contempla 0 processo de ensino-aprendizagem impositivo e doutrinário sem ambiente adequado o que dificulta o exercício do raciocínio crítico e reflexivo, essencial para a formação dessas duas áreas. Nesse sentido, utilizar uma estrutura menos formal e que demanda a participação dos alunos para a construção do ensino-aprendizagem como ocorre dentro de uma LAM pode vir a trazer bons frutos para o ensino de Ética e Bioética. Assim, o objetivo do estudo foi o de descrever e avaliar a implementação da Liga de Ética e Bioética (LiEBe) em seu primeiro ano na Faculdade de Ciências Médicas da Universidade de Campinas (FCM Unicamp).

\section{Resultados e Discussão}

A LiEBe foi coordenada por estudantes de medicina e profissionais do curso de Aprimoramento do Hospital das Clínicas, contando com auxilio técnico de professores ligados ao departamento de Clínica Médica e de Saúde Coletiva da FCM Unicamp. Ao todo foram dez encontros ao longo do ano de 2017, contando com a presença de alunos do instituto de Biologia, de Artes, Filosofia e Ciências Humanas em algumas atividades e do curso de Medicina em grande maioria. Os temas abordados tenderam a ser os mais diversos possíveis, contemplando discussão sobre paternalismo e autonomia, transexualidade, indústria farmacêutica, ética e genética, conflitos bioéticos ao nascimento, espiritualidade, finitude, processo produtivo dos alimentos, discussão de caso clínico e ética e arte.

O principal objetivo dos encontros foi o de estimular o participante à reflexão acerca do tema. Para isso, os condutores das atividades valeram-se de diversas ferramentas como discussão a partir de pequeno trecho de filme ou até mesmo de episódio de série, encenação de uma trama fictícia, apresentação e discussão de caso clínico, debate a partir da apresentação de uma obra clássica etc. Esse aspecto foi avaliado a partir de um questionário baseado na escala Likert e aplicado aos participantes que assinaram termo de consentimento livre esclarecido.

Os espaços foram palco de ricos debates onde o ligante fora conduzido à reflexão tanto de cunho pessoal quanto o aspecto profissional, visão colaborada quando observado os dados dos questionários. A proposta, desde o início, fora de promover ambientes em que o processo de reflexão e debate pudesse ser desenvolvido, uma vez que essa foi a forma considerada mais adequada para o processo de ensino e aprendizagem.

Por outro lado foi desenvolvido a extensão e a pesquisa, importantes pilares das LAMs. O contato inicial com os professores foi iniciado por meio das atividades. Ao mesmo tempo que vêm sendo programado como, por exemplo, a organização de simpósio com outras ligas de Ética e Bioética, o auxílio na divulgação quanto a iniciativas de pesquisa na área como o programa de Ética e Bioética do CREMESP e também a aproximação com outras ligas para organização de iniciativas conjuntas.

\section{Conclusões}

A criação e implementação de uma LAM é um processo trabalhoso e que necessita de dedicação. Configura-se em um espaço onde o protagonista é o aluno, tendo em sua mão um horizonte de experimentações possíveis. $O$ grande desafio é de não deixar-se reproduzir vícios acadêmicos. Apropriar-se integralmente do ensino, pesquisa e extensão, ampliando o objeto da prática contribuindo dessa maneira para a formação médica.

\section{Agradecimentos}

Projeto de pesquisa com fomento SAE/UNICAMP e vinculação ao CEP sob o CAAE: 64633817.3.0000.5404. 